\title{
基于植被覆盖度的宁夏灵武白芨滩自然保护区防风固 沙功能时空变化研究
}

\author{
宋 超 ${ }^{1}$, 余琦殷 ${ }^{2}$, 王瑞霞 ${ }^{3}$, 王 萍 $^{1}$, 王 $\quad$ 俊 $^{3}$,马 瑞 $^{3}$, 崔国发 ${ }^{1, *}$ \\ 1 北京林业大学生态与自然保护学院, 北京 100083 \\ 2 国家林业和草原局经济发展研究中心，北京 100714 \\ 3 宁夏灵武白夰滩国家级自然保护区管理局, 银川 751400
}

\begin{abstract}
摘要: 基于 MODIS-NDVI 时序数据, 利用像元二分模型估算宁夏灵武白菆滩自然保护区 2000-2019 年的年最大植被覆盖度, 分析保护区整体及不同管理站范围的植被覆盖度 (Fractional Vegetation Coverage, FVC) 时空变化特征, 并结合气象数据计算了 2000-2019 年该保护区生态系统防风固沙功能,并分析了其时空格局及其变化原因,结果表明: (1) FVC 在季节和年尺度上均 呈上升趋势, 年增长量达 0.013 ; 不同阶段的植被覆盖类型变化明显, 由第一阶段以低覆盖度类型为主逐渐转变为第五阶段以中 覆盖度类型为主; (2) 不同管理站范围的 FVC 变化趋势不同, 其中甜水河管理站、大泉管理站、羊场湾管理站及长流水管理站西 侧的 $\mathrm{FVC}$ 增长快, 且拟合好; (3) 该保护区潜在风蚀量、实际风蚀量均逐渐减少,防风固沙率逐渐上升, 防风固沙功能逐渐增强, 明显体现在第三、四、五阶段; (4)不同管理站范围的防风固沙功能均持续增强,其中大泉管理站的防风固沙率增幅最大,从第 一阶段的 $53.39 \%$ 升至第五阶段的 $74.44 \%$, 增幅达 $21.05 \%$; 临河白芨滩和马鞍山管理站防风固沙率增幅较小, 分别为 $15.81 \%$ 、 $15.50 \%$ 。总体来看,保护区 2000-2019 年的 FVC 增幅显著, 植被空间变化规律明显, 防风固沙功能整体上呈逐渐增强,一定程 度上说明了该保护区的生态保护建设成效显著。
\end{abstract}

关键词: 荒漠; 自然保护区;植被;防风固沙; 生态服务

\section{Spatio-temporal variation of windbreak and sand fixation functions based on vegetation coverage in Baijitan National Nature Reserve, Ningxia}

\author{
SONG Chao ${ }^{1}$, YU Qiyin ${ }^{2}$, WANG Ruixia ${ }^{3}$, WANG Ping ${ }^{1}$, WANG Jun ${ }^{3}$, MA Rui ${ }^{3}$, CUI Guofa, \\ 1 School of Ecology and Nature Conservation, Beijing Forestry University, Beijing 100083, China \\ 2 China National Forestry and Grassland Economics and Development Research Center, Beijing 100714, China \\ 3 Ningxia Lingwu Baijitan National Nature Reserve Administration, Yinchuan 751400, China
}

\begin{abstract}
On the basis of moderate-resolution imaging spectroradiometer-normalized difference vegetation Index ( MODISNDVI) time-series data, the maximum annual vegetation coverage from 2000 to 2019 was estimated using the pixel binary model. The temporal and spatial variation characteristics of the fractional vegetation cover ( FVC) of Baijitan National Nature Reserve in Ningxia (hereafter the Nature Reserve) and different management stations were analyzed. Combined with meteorological data, the windbreak and sand fixation functions of the Nature Reserve ecosystem from 2000 to 2019 were calculated, and the temporal and spatial patterns and the changes of the functions were analyzed. Results showed that (1) the FVC exhibited an increasing trend on the seasonal and annual scales, and the annual growth reached 0.013. The
\end{abstract}

基金项目:生物多样性保护目标的设计与评估技术(2018YFC0507200)

收稿日期: 2020-03-23; 网络出版日期:2021-02-24

*通讯作者 Corresponding author.E-mail: fa6716@163.com 
vegetation type characteristics of different stages were obvious, i.e. from the first stage mainly with low cover, which accounted for $75.22 \%$ of the total area of the Nature Reserve, to the fifth stage mainly with medium cover, which accounted for $66.13 \%$ of the total area of the Nature Reserve. (2) The FVC change trends of different management stations were different, i.e. the FVC in the west of Tianshuihe, Daquan, Yangchangwan and Changliushui management stations grew fast and was well distributed. (3) The potential and actual wind erosion amounts of the Nature Reserve gradually increased in the first stage and significantly increased in the third, fourth and fifth stages. (4) The windbreak and sand fixation functions in different management stations continuously increased, and the increase rate in Daquan management station was the largest, from $53.39 \%$ in the first stage to $74.44 \%$ in the fifth stage, with an increase of $21.05 \%$. In general, the FVC of the Nature Reserve increased significantly from 2000 to 2019, and the spatial variation of vegetation was significant. The windbreak and sand fixation functions were gradually enhanced, which indicated that the ecological protection construction of the Nature Reserve was remarkable.

Key Words : desert; Nature Reserve; vegetation; windbreak and sand fixation; ecological service

气候暖干化发展趋势使干旱半干旱地区生态环境受到荒漠化发展的胁迫, 植被覆盖度 (Fractional Vegetation Coverage, FVC) 及其时空变化是干旱半干旱地区反映植被质量、土地类型变化的重要指标之一, 可 以有效地表达植被分布状况及荒漠化程度, 是衡量地表植被状况及评价生态环境质量的重要手段 ${ }^{[1]}$ 。利用 遥感技术手段可以有效地监测植被覆盖和荒漠化发展趋势。土壤风蚀是我国干旱半干旱地区的严重环境问 题之一,所以,开展防风固沙功能研究对干旱半干旱地区具有重要的参考意义。

防风固沙功能是干旱半干旱地区生态系统提供的重要生态系统服务, 其物质量常通过风蚀模型进行计 算, 目前已有的研究模型包括 TEAM 模型 ${ }^{[2]}$ 、WEPS 模型 ${ }^{[3]}$ 、WEQ 模型 ${ }^{[4]}$ 、修正风蚀方程模型 $(\text { RWEQ })^{[5-8]}$ 等。 研究者们利用上述各类模型在不同地区进行了大量的风蚀模拟研究, 在众多模型中董治宝在以风洞实验和野 外观测的基础上建立的风蚀流失量模型 ${ }^{[9]}$, 被许多研究 ${ }^{[10-12]}$ 应用于中国干旱半干旱地区。

宁夏灵武白夰滩国家级自然保护区 ( 以下简称“白苃滩自然保护区”)位于毛乌素沙地边缘,在保护黄河、 维护周边生态安全、改善周边生态环境等方面起着重要的作用 ${ }^{[13]}$ 。然而, 这里曾经风沙危害严重, 对附近的 城市生活和工农业生产都造成较大影响。保护区自成立以来,通过多年探索, 构建了“五位一体”的防沙治沙

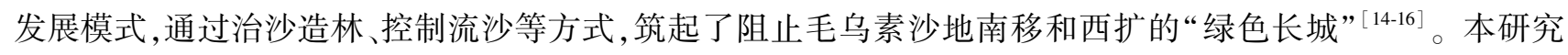
基于 MODIS-NDVI 时序数据, 利用像元二分模型估算白芨滩自然保护区的年最大 FVC, 分析保护区不同管 理站范围 FVC 的时空变化特征, 并结合气象数据, 通过风蚀模型估算了潜在风蚀量和实际风蚀量, 以两者差 值作为保护区防风固沙量, 分析了其防风固沙功能的时空格局及其变化原因, 为荒漠类自然保护区管理及可 持续发展提供科学参考。

\section{1 研究地概况}

白茂滩自然保护区于 2000 年 4 月晋升为国家级自然保护区, 地理坐标为 $106^{\circ} 20^{\prime} 22^{\prime \prime}-106^{\circ} 37^{\prime} 19^{\prime \prime} \mathrm{E}$, $37^{\circ} 49^{\prime} 05^{\prime \prime}-38^{\circ} 20^{\prime} 54^{\prime \prime} \mathrm{N}$, 地处毛乌素沙地边缘, 宁夏灵武市境内引黄灌区东部的荒漠区域, 生态环境比较脆 弱。保护区北部距银川市 $10 \mathrm{~km}$, 与宁夏河东机场相毗邻, 西部与青铜峡市、吴忠市紧邻, 与多条国道、省道相 通 ${ }^{[16]}$ 。保护区南北长 $61 \mathrm{~km}$, 东西宽 $21 \mathrm{~km}$, 总面积为 $748.43 \mathrm{~km}^{2}$, 约占灵武市总面积的 $1 / 4$, 其中核心区面积 为 $313.18 \mathrm{~km}^{2}$, 缓冲区面积为 $186.06 \mathrm{~km}^{2}$, 实验区面积为 $249.19 \mathrm{~km}^{2}$ (图 1)。

该保护区属于中温带干旱气候区, 具有典型的大陆性气候特征, 特点是干燥、雨量少而集中、蒸发量大、冬 季长、夏季热短、温差大、日照长、光能充足、冬春季风沙多、无霜期短。年平均降水量为 $192.9 \mathrm{~mm}$, 年最大降 水量为 $352.4 \mathrm{~mm}$, 年最小降水量为 $80.4 \mathrm{~mm}$, 日最大降水量为 $95.4 \mathrm{~mm}$, 最大积雪深度为 $130 \mathrm{~mm}$; 多年平均气 温为 $10.4{ }^{\circ} \mathrm{C}$, 积温 $3551.3^{\circ} \mathrm{C}, 1$ 月份平均气温最低, 约为 $-6.7^{\circ} \mathrm{C}, 7$ 月份最高, 约为 $24.7^{\circ} \mathrm{C}$, 年极端最高气温为 
$41.4{ }^{\circ} \mathrm{C}$, 年极端最低气温为 $-28{ }^{\circ} \mathrm{C}$; 年日照时数为 3011 $\mathrm{h}$; 年平均日照时数为 $2717 \mathrm{~h}, 7$ 月份平均日照时间最 长, 约为 $12.1 \mathrm{~h}, 12$ 月份最短, 约为 $9.5 \mathrm{~h}$ 。

\section{2 数据来源与处理}

\section{1 数据来源}

植被 指 数 遥感数 据 ( Normalized Difference Vegetation Index, NDVI) 来源于美国 NASA (National Aeronautics and Space Administration) 戈达德航天中心 MODIS ( Moderate-resolution Imaging Spectroradiometer) 时间分辨率为 $16 \mathrm{~d}$ 、空间分辨率为 $250 \mathrm{~m} \times 250 \mathrm{~m}$ 、格式 为 EOS-HDF 的 MOD13Q1 植被指数陆地标准产品 ( https://ladsweb. nascom. nasa. gov/), 本研究选取 $2000-2019$ 年全年数据集 (每年 23 期)。

气象数据采用中国气象科学数据共享服务网 (http://data.cma.cn/) 距离该保护区最近的灵武市气象 站( 编号:53614) 2000-2019 年逐日和逐月数据集,包含 风速、降水、温度和湿度等。灵武市气象站位于保护区西 北方向, 距保护区约 $3.7 \mathrm{~km}$, 地理坐标为 $106^{\circ} 12^{\prime} \mathrm{E}$, $38^{\circ} 28^{\prime} \mathrm{N}$ 。

数字高程模型 $(D E M)$ 数据采用中国科学院计算机

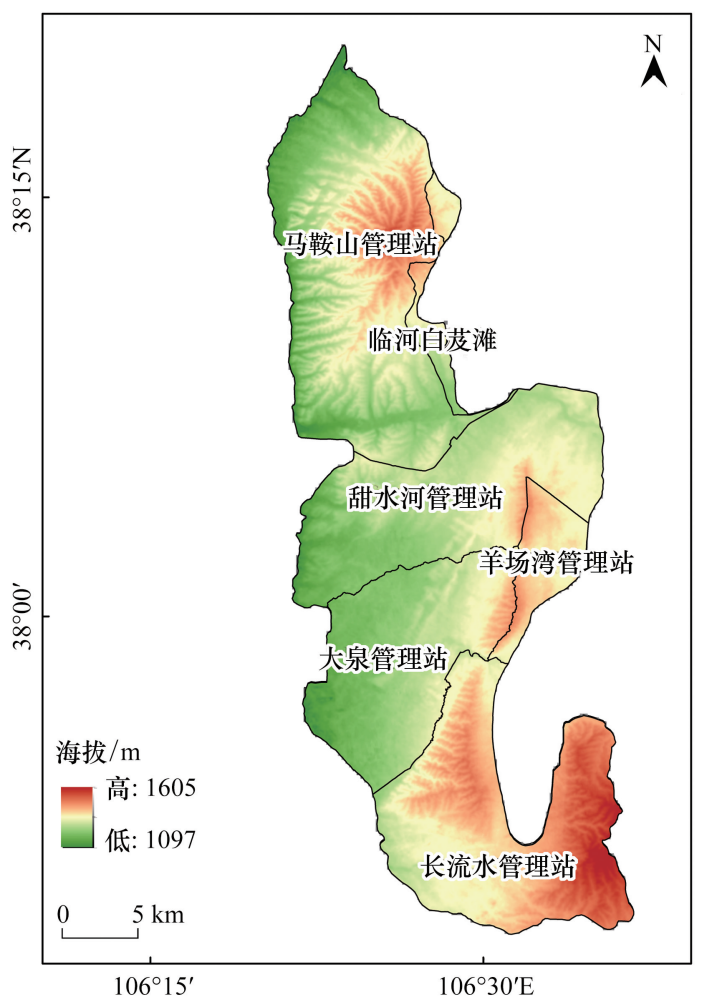

图 1 白苃滩自然保护区地形图

Fig.1 The DEM of Baijitan Nature Reserve 网络信息中心地理空间数据云平台 (http://www. gscloud.cn/) GDEMDEM 30M 分辨率数字高程数据。

\section{2 数据处理}

\subsubsection{NDVI 数据}

运用 ArcGIS10.7 软件把 HDF 格式的 NDVI 数据转化转换为 Tiff 格式,并对数据进行投影变换和裁剪。 坐标系统转换为地理坐标 CGCS2000_3_Degree_GK_CM_105E, 中央经线为 $105 \mathrm{E}$,东偏和西偏均为 $0 \mathrm{~m}$, 基准 面 (Datue) 为 D_China_2000。选取三次卷积法,重采样分辨率为 $250 \mathrm{~m}$, 然后利用白芨滩自然保护区的矢量边 界对其进行裁剪。采用最大值合成法和平均值法分别对相同季节、年份数据进行合成。

2.2.2 沙源范围

白夰滩自然保护区的地貌由三种类型组成,包括低山丘陵,缓坡丘陵和沙漠低山丘陵,其中低山丘陵和缓 坡丘陵的风蚀和水土流失严重, 土层较薄, 石砾较多,而沙漠低山丘陵东部以星月型沙丘链为主,西部则沙丘 高大密集,连绵起伏 ${ }^{[16]}$ 。可以看出,该保护区沙源范围主要在沙漠低山丘陵地区。为了排除石质山地、水域、 农田等非沙源范围区域, 购买影像时间为 2016 年 7 月 27 日, 分辨率为 $2 \mathrm{~m}$ 的遥感影像 (http://www.kosmosimage.com/), 运用 ENVI 软件进行监督分类和目视解译, 并结合现场调查, 确定沙源范围 (图 2)。

\subsection{3 气象数据}

沙尘天气主要发生在冬春季节, 这是由于该时期干旱半干旱地区降水甚少, 地表异常干燥松散, 抗风蚀能 力很弱,在有大风刮过时就会将大量沙尘卷人空中,形成沙尘天气 ${ }^{[17]}$ 。该保护区的 3-5 月风速大、降水少、 地表干燥, 为沙尘天气的频发时期 ${ }^{[16]}$, 故选取 3-5 月最大风速大于平均起沙风速 $(4.85 \mathrm{~m} / \mathrm{s})$ 的天数 ${ }^{[18]}$, 对气 象数据异常值进行线性插值处理, 根据当日平均风速和最大风速推算日大风时数, 并计算每年 $3-5$ 月大风 时数。 


\subsubsection{DEM 数据}

运用 ArcGIS10.7 软件, 使用数据管理工具依据保 护区矢量边界对 DEM 数据进行裁剪和重采样, 然后使 用空间分析工具计算坡度、坡向和高程。

\section{3 数据分析}

\subsubsection{FVC 计算与分析方法}

基于遥感数据估算 $\mathrm{FVC}$ 的方法主要有植被指数 法 $^{[19-20]}$ 、像元分解法 ${ }^{[21-22]}$ 、回归模型法等 ${ }^{[23-24]}$ 。本研究 采用植被指数法, 基于像元二分模型, 以 NDVI 数据为 基础,估算 $\mathrm{FVC}$,其公式为:

$$
\mathrm{FVC}=\frac{\mathrm{NDVI}-\mathrm{NDVI}_{\text {soil }}}{\mathrm{NDVI}_{\text {evg }}-\mathrm{NDVI}_{\text {soil }}}
$$

式中, $\mathrm{NDVI}_{\mathrm{evg}}$ 是纯植被像元值, 理论上接近于 1 , 但受植 被类型、土壤条件等因素随时空变化; $\mathrm{NDVI}_{\text {soil }}$ 是纯土壤 像元值, 理论上接近于 0 , 但受大气、地表湿度条件、地 表粗粘度、土壤类型、土壤颜色等因素随时空变化。目 前, 不同研究对 $\mathrm{NDVI}_{\text {evg }}$ 和 NDVI ${ }_{\text {soil }}$ 的取值方法有较大差 别 ${ }^{[25-30]}$, 本研究参考方杰诗等在没有详细的区域植被 和土壤光谱等数据时对银川市植被覆盖反演使用的近 似估值算法 ${ }^{[31-32]}$, 在计算时 $\mathrm{NDVI}_{\text {soil }}$ 取 $0.05 、 \mathrm{NDVI}_{\text {evg }}$ 取 0.7 。

参考毛乌素沙地 FVC 与植被地貌类型的关系的有 关研究 ${ }^{[33]}$, 将保护区 FVC 划分为劣覆盖度 $(<10 \%)$ 、低 覆盖度 $(10 \%-30 \%) 、$ 中覆盖度 $(30 \%-50 \%)$ 和高覆盖

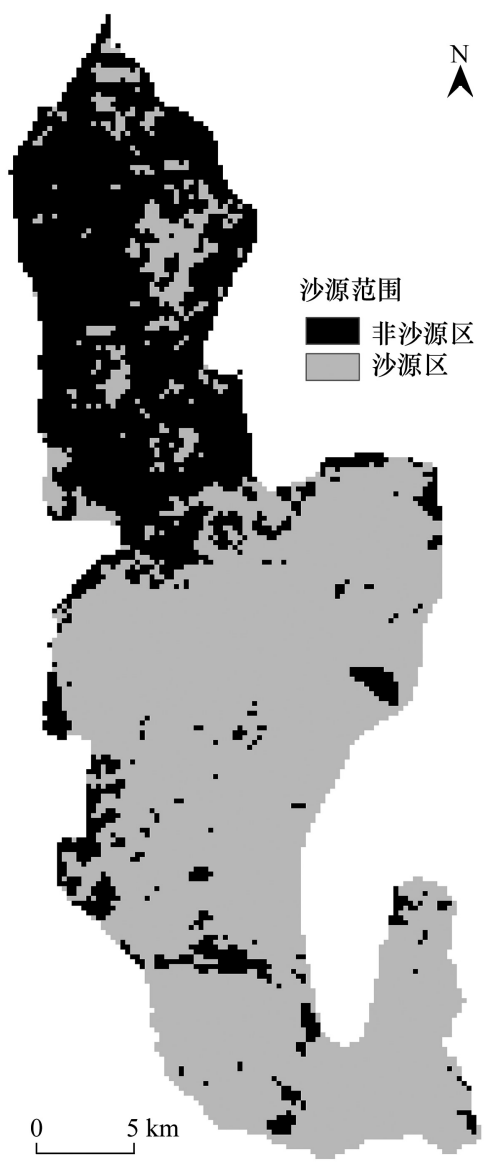

图 2 白芨滩自然保护区沙源范围

Fig.2 Sand source range of Baijitan Nature Reserve 度 $(>50 \%)$ 等 4 种类型。

运用 ArcGIS10.7 软件对 NDVI 数据进行统计和分析。首先, 采用最大值合成法和平均值法合成年最大 NDVI、季最大 NDVI, 估算年均 FVC 并分析其时间变化特征; 其次,采用趋势线分析法,其公式为:

$$
\text { slope }=\frac{n \times \sum_{i=1}^{n}\left(i \times \mathrm{NDVI}_{\mathrm{i}}\right)-\sum_{i=1}^{n} i \sum_{i=1}^{n} \mathrm{NDVI}_{\mathrm{i}}}{n \times \sum_{i=1}^{n} i^{2}-\left(\sum_{i=1}^{n} i\right)^{2}}
$$

其中, slope 为某像元年际变化斜率; $n$ 为研究时间年限 $(n=20) ; \mathrm{NDVI}_{\mathrm{i}}$ 为某像元第 $i$ 年的 NDVI 值。

根据 slope 和其 $R^{2}$ 的变化范围, 将植被覆盖变化规律定义为极明显发展类型、明显发展类型、缓慢发展类 型、稳定类型、缓慢逆转类型、明显逆转类型、极明显逆转类型等 7 个变化区间 ${ }^{[34]}$, 综合分析植被覆盖特点与 变化特征。具体变化区间划分如下: slope $<-0.01$ 且 $R^{2}>0.25$ 为极明显发展类型; $-0.01<$ slope $<-0.005$ 且 $R^{2}>$ 0.25 为明显发展类型; $-0.005<$ slope $<0$ 且 $R^{2}>0.25$ 为缓慢发展类型; $R^{2}<0.25$ 为稳定类型; $0<$ slope $<0.005$ 且 $R^{2}>0.25$ 为缓慢逆转类型 $; 0.005<$ slope $<0.01$ 且 $R^{2}>0.25$ 为明显逆转类型; slope $>0.01$ 且 $R^{2}>0.25$ 为极明显逆 转类型。

\subsection{2 防风固沙功能计算与分析方法}

防风固沙功能生态效益是指在风沙源区由于植被的作用减少大风对土壤表层颗粒吹扬, 避免下风向区域 沙尘灾害发生的范围与强度效应 ${ }^{[10]}$ 。风蚀量是衡量风沙源区沙害的重要指标之一 ${ }^{[10]}$ 。只有在起沙风的条 件下, 沙粒才开始运动。沙粒运动受众多因素的影响, 其中沙粒粒径为主要影响因素 ${ }^{[35]}$ 。该保护区沙粒以混 
合沙为主, 主要为细沙粒, 参考有关研究, 混合沙的平均粒径为 $0.2 \mathrm{~mm}$, 起沙风速为 $4.85 \mathrm{~m} / \mathrm{s}^{[36]}$, 并依据气象 数据计算每年在西风、西北风时的起沙时数与达到起沙风速的平均风速。

董治宝在以风洞实验和野外观测的基础上对陕西省六道沟小流域的风力侵蚀流失量建立了风蚀流失量 模型 ${ }^{[9]}$, 由于该流域地处毛乌素沙地东北边缘, 地貌类型为片沙覆盖的黄土丘陵, 与白菆滩自然保护区同处 毛乌素沙地边缘, 在地域和自然条件方面都非常接近, 韩永伟等、李柏延、马晓飞等研究也使用了该模 型 ${ }^{[9-11]}$, 且取得了良好的效果, 所以在估算白菆滩自然保护区风蚀量时, 以此模型为基础, 将研究区的遥感数 据分为 11811 个 $250 \mathrm{~m} \times 250 \mathrm{~m}$ 的栅格(因栅格精度和裁剪的原因, 计算中保护区总面积与实际有约 $10 \mathrm{~km}^{2}$ 误 差), 通过计算沙源范围每一个栅格的风蚀量,逐一相加得出该保护区风蚀量,具体沙地风蚀量模型如下:

$$
Q=\iint_{t} \int_{x} \int_{y}\left\{3.90\left(1.0413+0.04413 \theta+0.0021 \theta^{2}-0.0001 \theta^{3}\right) \times\left[\frac{V^{2}\left(8.2 \times 10^{-5}\right)^{V_{C R}} S_{D R}^{2}}{\left(H^{8} d^{2} F\right) x, y, t}\right]\right\} d_{x} d_{y} d_{t}
$$

式中: $Q$ 为风蚀量 $(\mathrm{t}) ; \theta$ 为坡度 $\left({ }^{\circ}\right)$, 由高程数据计算获取; $V$ 为风速 $(\mathrm{m} / \mathrm{s})$, 由每年达到起沙风速的平均风速 计算; $V_{C R}$ 为 $\mathrm{FVC}(\%), S_{D R}$ 为人为地表结构破损率 $(\%)$, 本研究中不考虑人为地表结构破损率, 取 $1 ; H$ 为空气 相对湿度 $(\%)$, 根据保护区气象数据的平均值取 $0.35 ; d$ 为土壤粒径 $(\mathrm{mm})$, 取保护区沙粒的平均粒径 0.2 $\mathrm{mm} ; F$ 为土体硬度 $\left(\mathrm{N} / \mathrm{cm}^{2}\right)$, 参考土壤质地模型参数表, 取 $0.9 \mathrm{~N} / \mathrm{cm}^{2} ; t$ 为时间 $(\mathrm{s})$, 由气象数据计算的年起沙 时数; $x, y$ 为距离参照点距离 $(\mathrm{km})$, 根据栅格大小取 $0.25 \mathrm{~km}$ 。

潜在风蚀量和实际风蚀量的差值即为植被减少风蚀的防风固沙量, 防风固沙量和潜在风蚀量的比值即为 防风固沙率。

$$
\begin{aligned}
& Q_{c}=Q_{w}-Q_{s} \\
& R=Q_{c} / Q_{s}
\end{aligned}
$$

式中: $Q_{c}$ 为防风固沙量 $(\mathrm{t}) ; Q_{w}$ 为假设无植被覆盖情况下的潜在风蚀量 $(\mathrm{t}) ; Q_{s}$ 为实际风蚀量 $(\mathrm{t}) ; R$ 为防风固 沙率。

\section{3 结果与分析}

3.1 白苃滩自然保护区 FVC 时空变化分析

3.1.1 年均 FVC 空间分布特征

该保护区有马鞍山管理站、临河白芨滩、甜水河管理站、羊场湾管理站、大泉管理站、长流水管理站等 6 个 管理站, 其中马鞍山管理站和临河白芨滩海拔较高, 主要为山地丘陵; 甜水河管理站、大泉管理站及羊场湾管 理站地势平坦, 主要为沙地; 长流水管理站丘陵和沙地均有分布 ${ }^{[16]}$, 西侧海拔低于 $1400 \mathrm{~m}$ 的地区多为沙地, 东侧多为丘陵。通过实地踏查, 结合管理站及其分布特征 ${ }^{[16]}$, 将其划分为三个区域 (表 1)。

表 1 白菠滩自然保护区区域划分

Table 1 The regional divisions of Baijitan Nature Reserve management station

\begin{tabular}{lll}
\hline 区域 & 管理站 & 主要特征 ${ }^{[16]}$ \\
Area & Management station & Main characteristics \\
\hline 北部地区 Northern part & 马鞍山管理站、临河白菠滩 & 低山丘陵 \\
中部地区 Central part & 甜水河管理站、大泉管理站、羊场湾管理站 & 沙漠低山丘陵 \\
东南部地区 Southeastern part & 长流水管理站 & 低缓丘陵 \\
\hline
\end{tabular}

保护区年均 FVC 空间分布规律( 图 3) 主要表现为:

(1) 北部地区为以低山丘陵为主, 占保护区总面积的 $33.10 \%$ 。主要植被覆盖类型为低覆盖度和中覆盖 度, 分别占保护区总面积的 $22.67 \% 、 10.35 \%$, 高覆盖度类型零星分布, 仅占保护区总面积的 $0.08 \%$; 无劣覆盖 度植被类型分布。

(2) 中部地区以沙漠低山丘陵为主, 占保护区总面积的 $43.33 \%$ 。低覆盖度类型占比最高, 占保护区总面 
积的 $32.29 \%$, 其次分别为中覆盖度、劣覆盖度、高覆盖 度类型, 分别占保护区总面积的 $9.26 \% 、 1.13 \% 、 0.64 \%$ 。

(3) 东南部地区低缓丘陵为主, 占保护区总面积的 $23.57 \%$ 。其中, 低覆盖度类型占保护区总面积的 $7.8 \%$; 中覆盖度类型占比为 $15.77 \%$, 是该植被类型在保护区 的主要分布地。

3.1.2 FVC 时间变化特征

为了研究白苃滩自然保护区不同时段 FVC 的变化 趋势, 本研究结合保护区建设和总体规划情况,将保护 区的发展历程划分为 5 个阶段 (表 2), 以便于分阶段对 其变化特征进行分析。

保护区 FVC 时间变化特征 (图 4一图 6) 主要表 现为:

(1) 春季、夏季、秋季、冬季 FVC 均呈稳定增长趋 势, 增长量近似相同, 分别为 $0.0181 、 0.0205 、 0.0195$ 、 0.0195 , 其 $R^{2}$ 分别为 $0.8753,0.9228,0.9076,0.9247$, 经 $F$ 显著性检验, $F_{\text {春 }}=126.33, F_{\text {夏 }}=215.31, F_{\text {秋 }}=178.89, F_{\text {冬 }}=$ 220.99 , 经查 $F$ 检验表, $F_{\alpha}=0.05(1,18)=8.28$, 模型拟 合度 $F$ 检验均达极显著。

(2) 年均 FVC 呈稳定增长趋势, 年均增长量为 0.0130 , 其 $R^{2}$ 为 0.7759 , 经 $F$ 显著性检验, $F_{\text {年平均 }}=62.34$, 经查 $F$ 检验表, $F_{\alpha}=0.05(1,18)=8.28$, 模型拟合度 $F$ 检验达 极显著。

(3) 不同阶段的植被类型特征明显。第一阶段以

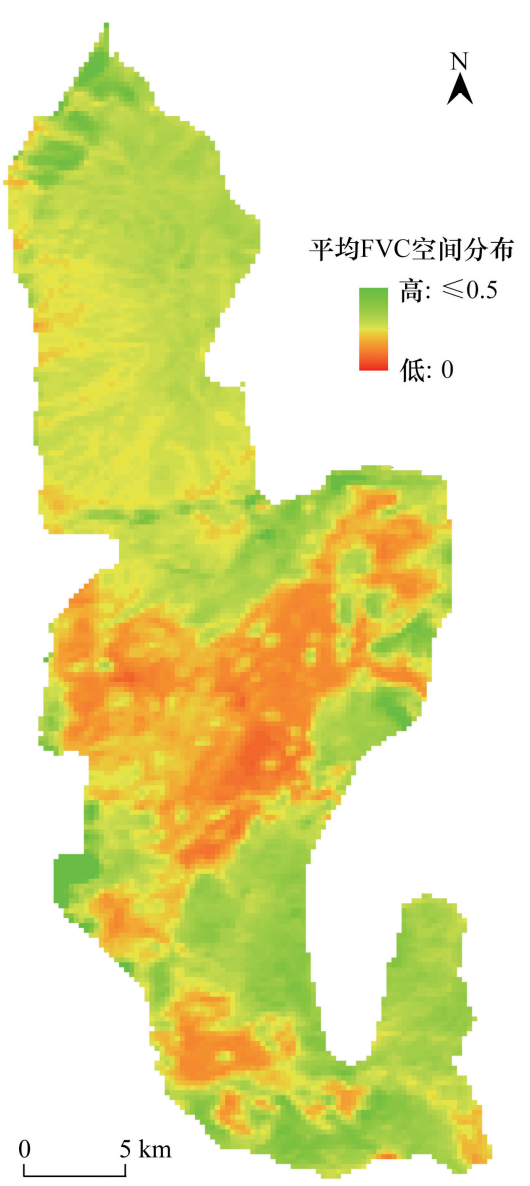

图 3 白芨滩自然保护区 2000-2019 年平均 FVC 空间分布

Fig.3 The spatial distribution of FVC in Baijitan Nature Reserve from 2000 to 2019 低覆盖度类型为主,其面积为 $555.25 \mathrm{~km}^{2}$, 占保护区总 面积的 $75.22 \%$; 其次为劣覆盖度类型, 面积为 $155.88 \mathrm{~km}^{2}$, 占 $21.11 \%$; 中覆盖度与高覆盖度类型分布极少, 二 者仅占保护区总面积的 $3.67 \%$ 。第二阶段的劣覆盖度类型减少, 低覆盖度类型占比仍最高, 为 $81.95 \%$, 中覆 盖度和高覆盖度类型的面积有所上升, 分别增长了 $3.39 \% 、 0.08 \%$ 。第三阶段的低覆盖度、中覆盖度类型明显 增加, 成为该阶段的主要类型, 二者占比达 $94.90 \%$ 。第四阶段的劣覆盖度类型成为占比最小的类型, 仅占 0 . $32 \%$, 中覆盖度类型仍以较快速度增长, 超过了低覆盖度类型的面积, 成为占比最大的植被覆盖类型, 占比达 $54.96 \%$ 。第五阶段的低覆盖度逐渐转化为中覆盖度类型, 两者面积差增大, 中覆盖度类型占比达 $66.13 \%$; 高 覆盖度类型明显增加, 其面积达 $100.81 \mathrm{~km}^{2}$ 。

表 2 白苏滩自然保护区发展阶段划分

Table 2 The development stage division of Baijitan Nature Reserve

\begin{tabular}{lll}
\hline 发展历程 History & 时间 Period & 建设阶段特征 The feature of stage \\
\hline 第一阶段 First stage & $2000-2003$ 年 & 晋升国家级自然保护区初期 \\
第二阶段 Second stage & $2004-2007$ 年 & 保护区基础设施建设规范化 \\
第三阶段 Third stage & $2008-2011$ 年 & 第一次边界范围、面积和功能分区调整后 \\
第四阶段 Fourth stage & $2012-2015$ 年 & 第二次边界范围、面积和功能分区调整后,新一轮总体规划实施初期 \\
第五阶段 Fifth stage & $2016-2019$ 年 & 总体规划的近期规划实施完成,远期规划开始实施 \\
\hline
\end{tabular}

3.1.3 FVC 变化趋势的空间分布特征

根据白夰滩自然保护区 $\mathrm{FVC}$ 年际变化率(图 7), 甜水河管理站、大泉管理站、羊场湾管理站、长流水管理 


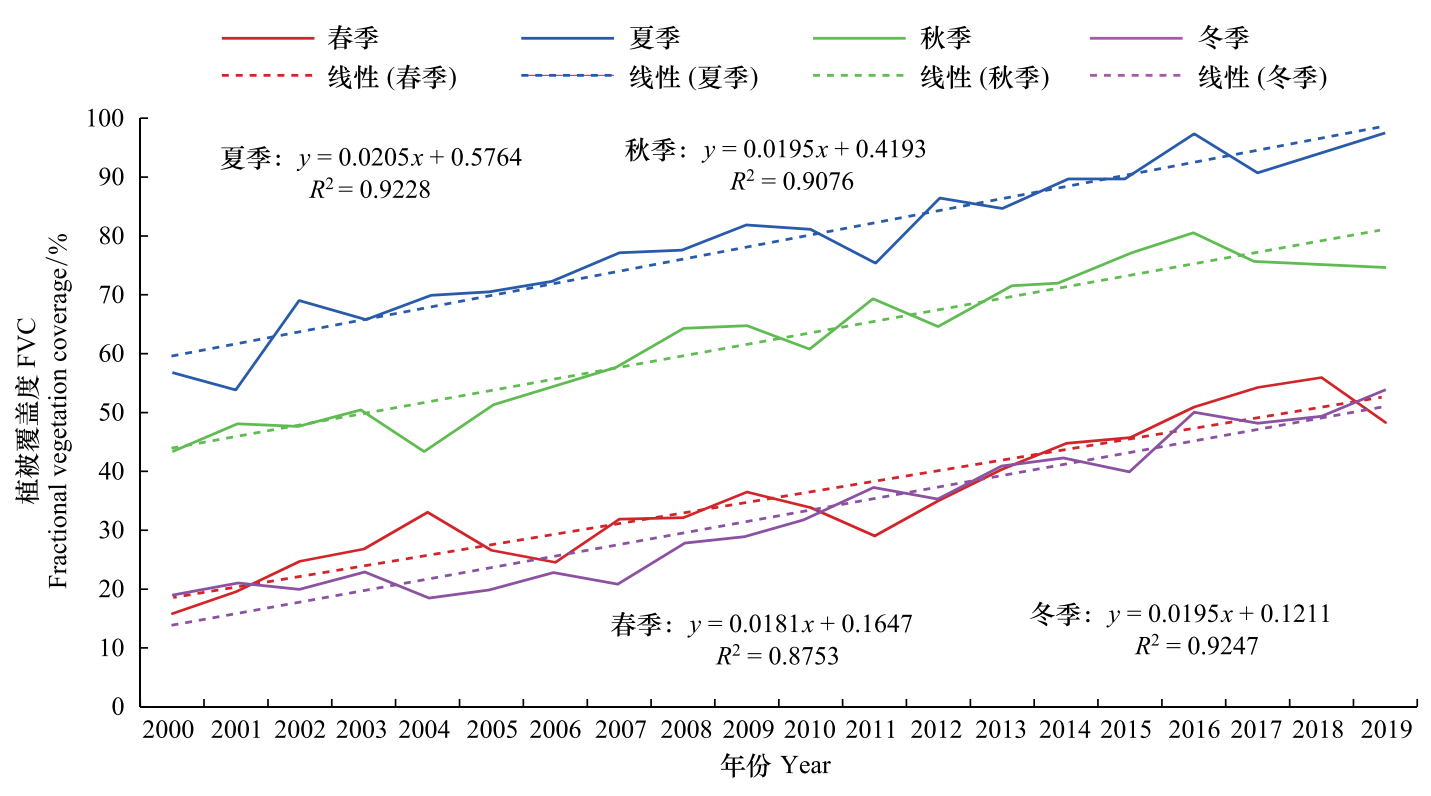

图 4 白苃滩自然保护区 FVC 季节变化趋势

Fig.4 The seasonal variation trend of FVC in Baijitan Nature Reserve

站西侧、长流水管理站东侧、马鞍山管理站、临河白菆滩 年均 FVC 的平均斜率分别为 $0.0133 、 0.0161 、 0.0164$ 、 $0.0153 、 0.0059 、 0.0115 、 0.0102$, 平均 $R^{2}$ 分别为 0.7376 、 $0.7895 、 0.7579 、 0.6865 、 0.3546 、 0.4304 、 0.3378$ 。由此可 以看出,甜水河管理站、大泉管理站、羊场湾管理站及长 流水管理站西侧的 FVC 比马鞍山管理站、临河白芨滩 及长流水管理站东侧的 FVC 增长快, 且拟合好。

根据各管理站基于 NDVI 的 FVC 变化趋势分级 (表 3),该保护区的植被变化趋势主要表现为稳定类 型、缓慢逆转类型、明显逆转类型和极明显逆转类型。 保护区的中部地区与其他地区的变化趋势具有明显差 异,主要表现为稳定类型、极明显逆转类型的占比差异

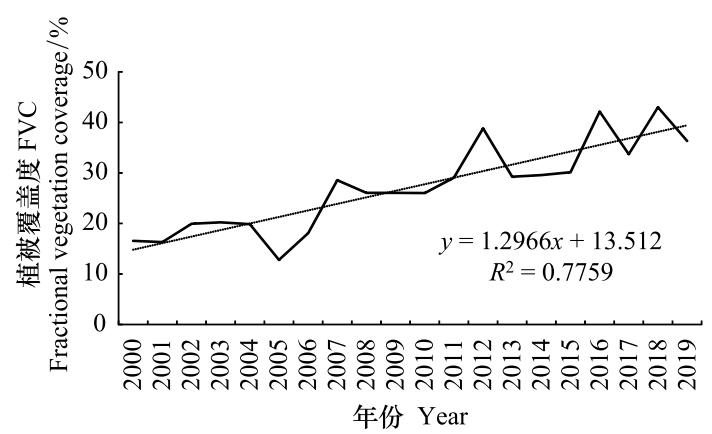

图 5 白芨滩自然保护区年均 FVC 变化趋势

Fig. 5 The interannual variation trend of FVC in Baijitan Nature Reserve 大,其中中部地区即甜水河管理站、大泉管理站、羊场湾管理站的稳定类型相对较少,分别占管理站面积的 $0.99 \% 、 0.05 \% 、 3.7 \%$, 而北部地区的马鞍山管理站、临河白芨滩的稳定类型占比则相对较高, 分别为 $14.20 \%$ 、 $19.15 \%$; 甜水河管理站、大泉管理站、羊场湾管理站极明显逆转稳定类型比例相对较高, 占管理站面积的 $27.46 \% 、 53.14 \% 、 56.92 \%$, 而马鞍山管理站、临河白芨滩的稳定类型占比则相对较低,占比分别为 $13.14 \%$ 、 $4.61 \%$; 长流水管理站的植被变化趋势主要为明显逆转类型, 其占比为 $50.25 \%$, 稳定类型与极明显逆转类型次 之, 分别占 $16.04 \% 、 26.62 \%$,缓慢逆转类型占比最低。

3.2 白苄滩自然保护区防风固沙功能变化分析

3.2.1 防风固沙功能总体变化趋势

根据白夰滩自然保护区达到起沙风速的时数与风速的年变化规律显示 (图 8), 保护区整体起沙时数呈下 降趋势 $\left(R^{2}=0.682\right)$, 其减少量为 $1.19 \mathrm{~d} / \mathrm{a}$, 其中 2006 年起沙时数最高, 达 $30.92 \mathrm{~d}, 2015$ 年起沙时数最低, 仅为 $4.72 \mathrm{~d}$; 达到起沙风速的平均风速呈缓慢波动下降趋势, 但变化趋势不明显 $\left(R^{2}=0.109\right)$, 其年减少量为 0.26 $\mathrm{m} / \mathrm{s}$ 。 

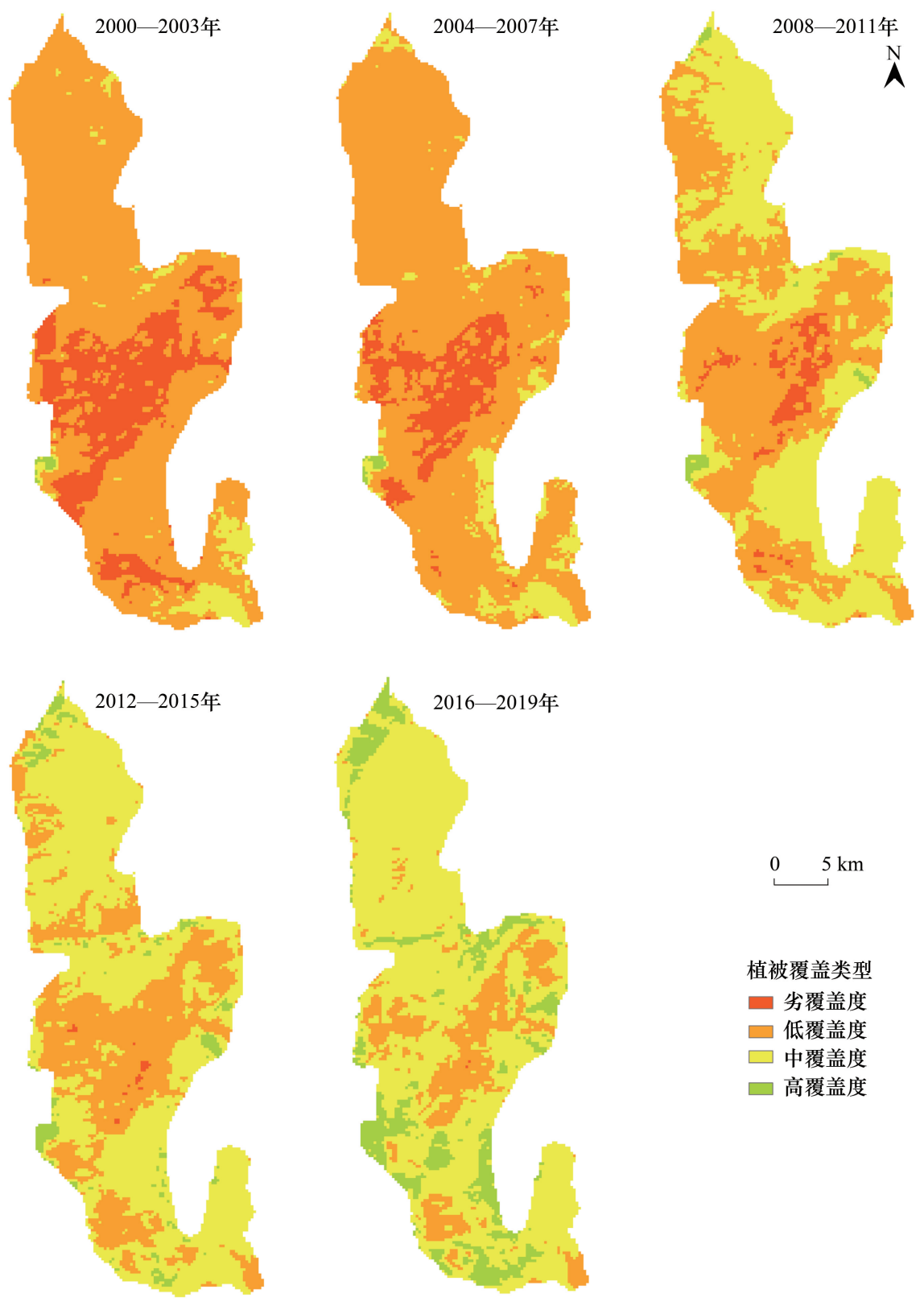

图 6 白芨滩自然保护区不同阶段 FVC 空间分布

Fig.6 The spatial distribution law of FVC in different stages

白芝滩自然保护区风速逐渐降低, 潜在风蚀量、实际风蚀量均逐渐减少, 防风固沙率上升, 防风固沙功能 整体上逐渐增强 (表 4)。第一、二阶段的防风固沙功能缓慢增强, 第一阶段的防风固沙率为 $58.37 \%$, 年均实 际风蚀量为 $2.46 \times 10^{5} \mathrm{t}$; 第二阶段防风固沙率为 $59.76 \%$, 增加了 $1.39 \%$, 年均实际风蚀量为 $1.70 \times 10^{5} \mathrm{t}$, 较第一 阶段减少 $30.89 \%$ 。第三、四、五阶段的防风固沙功能明显增强, 其中第三阶段的实际风蚀量出现显著下降, 为 $4.35 \times 10^{4} \mathrm{t}$, 仅为第一、二阶段的 $17.68 \% 、 25.59 \%$, 防风固沙率为 $65.98 \%$, 增加了 $6.22 \%$; 第四、五阶段的实际风 蚀量分别为 $2.62 \times 10^{4} \mathrm{t} 、 1.87 \times 10^{4} \mathrm{t}$, 防风固沙率持续上升, 分别为 $70.82 \% 、 75.43 \%$ 。

3.2.2 不同地区防风固沙功能变化趋势

该保护区不同地区的防风固沙功能主要表现为以下几个特征(表 5):

(1) 晋升为国家级自然保护区初期,马鞍山管理站、临河白芨滩和长流水管理站的防风固沙率分别为 


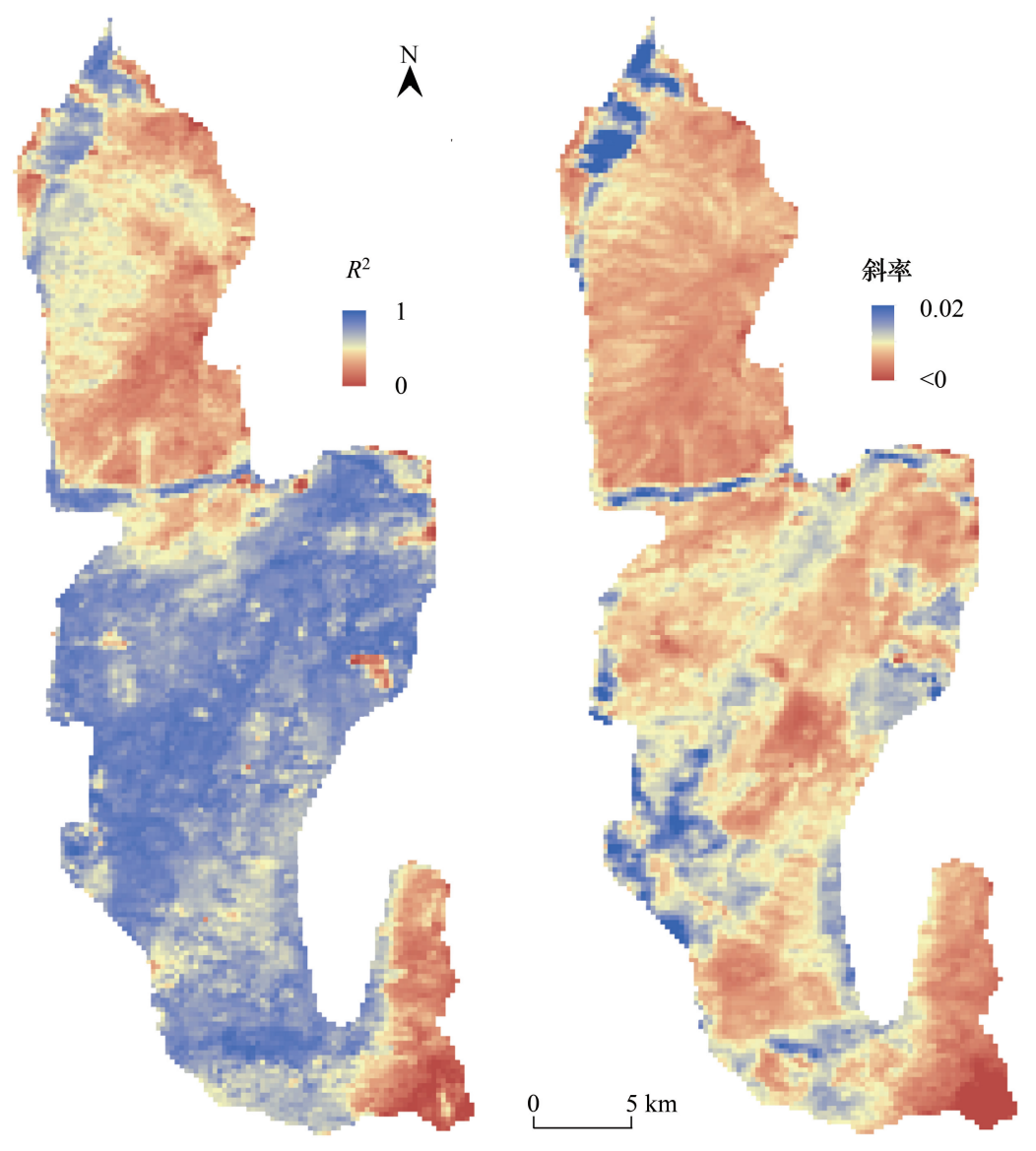

图 7 白菠滩自然保护区 $\mathbf{F V C}$ 年际变化率 ( $R^{2}$ 和斜率 $)$

Fig.7 The rate of interannual change of FVC in Baijitan Nature Reserve $\left(R^{2}\right.$ and slope $)$

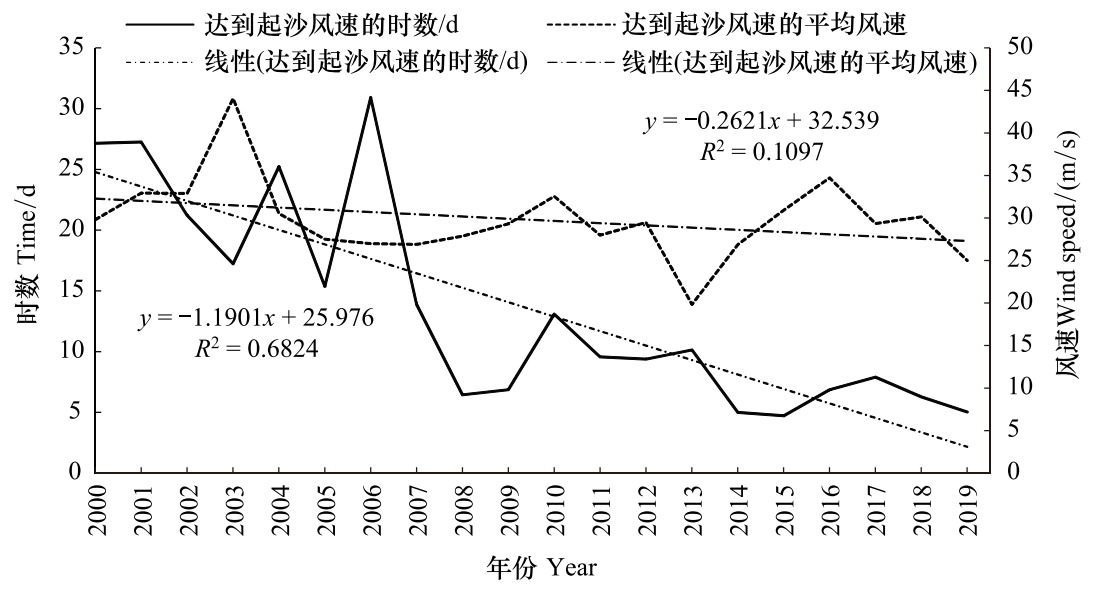

图 8 达到起沙风速的天数与风速的年变化规律

Fig.8 The interannual variation law and the days of the wind over sand-driving wind speed

$61.95 \% 、 61.68 \% 、 59.94 \%$,均高于保护区整体水平; 以劣覆盖度和低覆盖度为主要植被覆盖类型的大泉管理 站、甜水河管理站、羊场湾管理站的防风固沙能力则相对较弱,防风固沙率分别为 $53.39 \% 、 55.11 \% 、 56.78 \%$, 均低于保护区整体水平; 
表 3 白苃滩保护区植被变化趋势分级

Table 3 The trend classification in Baijitan National Nature Reserve

\begin{tabular}{|c|c|c|c|c|c|c|c|c|}
\hline $\begin{array}{c}\text { 管理站 } \\
\text { Management } \\
\text { stations }\end{array}$ & & $\begin{array}{c}\text { 极明显 } \\
\text { 发展类型 } \\
\text { Extremely } \\
\text { obvious } \\
\text { development }\end{array}$ & $\begin{array}{c}\text { 明显发展类型 } \\
\text { Obvious } \\
\text { development }\end{array}$ & $\begin{array}{c}\text { 缓慢发展类型 } \\
\text { Slow } \\
\text { development }\end{array}$ & $\begin{array}{l}\text { 稳定类型 } \\
\text { Stable type }\end{array}$ & $\begin{array}{c}\text { 缓慢逆转类型 } \\
\text { Slow } \\
\text { reversal }\end{array}$ & $\begin{array}{c}\text { 明显逆转类型 } \\
\text { Obvious } \\
\text { reversal }\end{array}$ & $\begin{array}{c}\text { 极明显 } \\
\text { 逆转类型 } \\
\text { Extremely } \\
\text { obvious } \\
\text { reversal }\end{array}$ \\
\hline \multirow[t]{2}{*}{ 甜水河 } & 占管理站面积 & 0 & 0 & 0 & $0.99 \%$ & $3.58 \%$ & $67.97 \%$ & $27.46 \%$ \\
\hline & 占保护区面积 & 0 & 0 & 0 & $0.21 \%$ & $0.76 \%$ & $14.48 \%$ & $5.85 \%$ \\
\hline \multirow[t]{2}{*}{ 大泉 } & 占管理站面积 & 0 & 0 & 0 & $0.05 \%$ & $7.85 \%$ & $38.97 \%$ & $53.14 \%$ \\
\hline & 占保护区面积 & 0 & 0 & 0 & $0.01 \%$ & $1.39 \%$ & $6.89 \%$ & $9.40 \%$ \\
\hline \multirow[t]{2}{*}{ 羊场湾 } & 占管理站面积 & 0 & 0 & 0 & $3.70 \%$ & $0.58 \%$ & $38.79 \%$ & $56.92 \%$ \\
\hline & 占保护区面积 & 0 & 0 & 0 & $0.16 \%$ & $0.03 \%$ & $1.68 \%$ & $2.47 \%$ \\
\hline \multirow[t]{2}{*}{ 长流水 } & 占管理站面积 & 0 & 0 & $0.18 \%$ & $16.04 \%$ & $6.91 \%$ & $50.25 \%$ & $26.62 \%$ \\
\hline & 占保护区面积 & 0 & 0 & $0.04 \%$ & $3.78 \%$ & $1.63 \%$ & $11.83 \%$ & $6.27 \%$ \\
\hline \multirow[t]{2}{*}{ 马鞍山 } & 占管理站面积 & 0 & 0 & 0 & $14.20 \%$ & $9.35 \%$ & $63.11 \%$ & $13.34 \%$ \\
\hline & 占保护区面积 & 0 & 0 & 0 & $4.36 \%$ & $2.87 \%$ & $19.38 \%$ & $4.10 \%$ \\
\hline \multirow[t]{2}{*}{ 临河白苃滩 } & 占管理站面积 & 0 & 0 & 0 & $19.15 \%$ & $3.55 \%$ & $72.70 \%$ & $4.61 \%$ \\
\hline & 占保护区面积 & 0 & 0 & 0 & $0.46 \%$ & $0.08 \%$ & $1.74 \%$ & $0.11 \%$ \\
\hline
\end{tabular}

表 4 白茂滩自然保护区年均防风固沙能力

Tabel 4 Annual average conserving ability of windbreak and sand fixation in Baijitan Nature Reserve

\begin{tabular}{lcccc}
\hline & $\begin{array}{c}\text { 第一阶段 } \\
\text { First stage }\end{array}$ & $\begin{array}{c}\text { 第二阶段 } \\
\text { Second stage }\end{array}$ & $\begin{array}{c}\text { 第三阶段 } \\
\text { Third stage }\end{array}$ & $\begin{array}{c}\text { 第四阶段 } \\
\text { Fourth stage } \\
\text { Fifth stage }\end{array}$ \\
\hline $\begin{array}{l}\text { 防风固沙量/(t/a) } \\
\text { Windbreak and sand fixation }\end{array}$ & $5.51 \times 10^{6}$ & $4.05 \times 10^{6}$ & $1.35 \times 10^{6}$ & $1.02 \times 10^{6}$ \\
$\begin{array}{l}\text { 潜在风蚀量/(t/a) } \\
\text { Potential wind erosion }\end{array}$ & $9.44 \times 10^{6}$ & $6.77 \times 10^{6}$ & $2.05 \times 10^{6}$ & $1.43 \times 10^{6}$ \\
$\begin{array}{l}\text { 实际风蚀量/(t/a) } \\
\text { Actual wind erosion }\end{array}$ & $2.46 \times 10^{5}$ & $1.70 \times 10^{5}$ & $4.35 \times 10^{4}$ & $2.62 \times 10^{4}$ \\
$\begin{array}{l}\text { 防风固沙率/\% } \\
\text { Windbreak and sand fixation rate }\end{array}$ & 58.37 & 59.76 & 65.98 & $7.87 \times 10^{4}$ \\
\hline
\end{tabular}

(2)不同地区的防风固沙功能均持续增大,其中大泉管理站的防风固沙率增幅最大,达 $21.05 \%$,防风固沙 率达到了 74.44\%,但仍不及保护区的整体水平; 临河白芨滩和马鞍山管理站防风固沙率增幅较小, 分别为 $15.81 \% 、 15.50 \%$,但仍高于保护区整体水平上;其他管理站的防风固沙率增幅在 16.19-16.96\% 之间。

表 5 白莈滩自然保护区防风固沙率时空变化规律

Table 5 Temporal and spatial variation of windbreak and sand fixation rate in Baijitan Nature Reserve

\begin{tabular}{cccccc}
\hline $\begin{array}{c}\text { 各站防风固沙率/\% } \\
\text { Windbreak and sand fixation rate }\end{array}$ & $\begin{array}{c}\text { 第一阶段 } \\
\text { First stage }\end{array}$ & $\begin{array}{c}\text { 第二阶段 } \\
\text { Second stage }\end{array}$ & $\begin{array}{c}\text { 第三阶段 } \\
\text { Third stage }\end{array}$ & $\begin{array}{c}\text { 第四阶段 } \\
\text { Fourth stage }\end{array}$ & $\begin{array}{c}\text { 第五阶段 } \\
\text { Fifth stage }\end{array}$ \\
\hline 甜水河 & $55.11 \%$ & $56.35 \%$ & $60.86 \%$ & $66.57 \%$ & $72.07 \%$ \\
大泉 & $53.39 \%$ & $55.09 \%$ & $62.05 \%$ & $67.25 \%$ & $74.44 \%$ \\
羊场湾 & $56.78 \%$ & $59.35 \%$ & $65.80 \%$ & $71.56 \%$ & $72.97 \%$ \\
长流水 & $59.94 \%$ & $61.25 \%$ & $68.51 \%$ & $72.96 \%$ & $76.60 \%$ \\
马鞍山 & $61.95 \%$ & $63.13 \%$ & $69.20 \%$ & $73.59 \%$ & $77.45 \%$ \\
临河白菆滩 & $61.68 \%$ & $63.52 \%$ & $70.34 \%$ & $73.33 \%$ & $77.49 \%$ \\
\hline
\end{tabular}

\subsection{3 防风固沙功能的比较}

为深人分析保护区防风固沙功能特点,将该保护区防风固沙能力与其他干旱半干旱地区的做横向对比 (表 6), 对比地区包括黑河下游重要生态功能区 ${ }^{[10]}$ 、银川盆地 ${ }^{[11]}$ 、京津风沙源区 ${ }^{[37]}$ 、锡林郭勒盟风沙源治理 
工程区 ${ }^{[38]}$ 等。其中,该保护区面积最小, 年均防风固沙能力最强,达到了 $966.58 \mathrm{t} \mathrm{km}^{-2} \mathrm{a}^{-1}$ 。京津风沙源区、 锡林郭勒盟风沙源治理工程区的面积大, 且年防风固沙量均超过了 $10^{10} \mathrm{t}$, 但年均防风固沙能力相对较弱, 分 别为 $68.24 \mathrm{t} \mathrm{km}^{-2} \mathrm{a}^{-1} 、 74.78 \mathrm{t} \mathrm{km}^{-2} \mathrm{a}^{-1}$, 可能是由于这些地区含有未有效用于防风固沙功能的土地利用类型。

表 6 白䓅滩自然保护区防风固沙能力对比

Table 6 Comparison of windbreak and sand fixation capacity

\begin{tabular}{|c|c|c|c|c|}
\hline $\begin{array}{l}\text { 研究地区 } \\
\text { Study area }\end{array}$ & $\begin{array}{c}\text { 面积 } / \mathrm{km}^{2} \\
\text { Area }\end{array}$ & $\begin{array}{l}\text { 计算年份 } \\
\quad \text { Year }\end{array}$ & $\begin{array}{c}\text { 年防风固沙量/ }(\mathrm{t} / \mathrm{a}) \\
\text { Annual windbreak } \\
\text { and sand fixation }\end{array}$ & $\begin{array}{c}\text { 年均防风固沙能力 } /\left(\mathrm{t} \mathrm{km}^{-2} \mathrm{a}^{-1}\right) \\
\text { Ability of annual windbreak } \\
\text { and sand fixation }\end{array}$ \\
\hline $\begin{array}{l}\text { 白芝滩自然保护区 } \\
\text { Baijitan Nature Reserve }\end{array}$ & $7.38 \times 10^{2}$ & 2019 & $7.14 \times 10^{5}$ & 966.58 \\
\hline $\begin{array}{l}\text { 黑河下游重要生态功能区 } \\
\text { Key eco-function zone in the lower reaches } \\
\text { of Heihe River }\end{array}$ & $1.11 \times 10^{4}$ & 2006 & $6.30 \times 10^{7}$ & 525.672 \\
\hline $\begin{array}{l}\text { 银川盆地 }{ }^{[11]} \\
\text { Yinchuan basin }\end{array}$ & $1.44 \times 10^{4}$ & 2014 & $7.20 \times 10^{6}$ & 499.83 \\
\hline $\begin{array}{l}\text { 京津风沙源区 }{ }^{[37]} \\
\text { Beijing-Tianjin sand source district }\end{array}$ & $4.58 \times 10^{5}$ & $2000-2015$ & $1.88 \times 10^{10}$ & 68.24 \\
\hline $\begin{array}{l}\text { 锡林郭勒盟风沙源治理工程区 }{ }^{[38]} \\
\text { Wind and sand source control project area } \\
\text { in Xilingol League }\end{array}$ & $2.03 \times 10^{5}$ & $2000-2015$ & $1.46 \times 10^{10}$ & 74.78 \\
\hline
\end{tabular}

\section{4 结论}

本研究基于 MODIS-NDVI 数据分析了 2000-2019 年白芨滩自然保护区植被覆盖变化情况,并以此为基 础估算了保护区防风固沙功能。主要结论如下:

（1）2000-2019 年,该保护区在季节尺度和年尺度上的 FVC 增长趋势均达到了极显著,其中夏季 FVC 自 2016 年以来均超过了 0.90 ,年均 FVC 也从 0.15 增长到 0.30 左右; 该保护区的植被覆盖类型也发生了较大转 变,劣覆盖度、低覆盖度、中覆盖度和高覆盖度类型分别由第一阶段占保护区总面积的 $21.12 \% 、 75.22 \%$ 、 $3.39 \% 、 0.27 \%$ 转变为第五阶段的 $0.02 \% 、 20.19 \% 、 66.13 \% 、 13.66 \%$ 。劣覆盖度与低覆盖度类型均显著减少, 其 中减少面积达 $561.79 \mathrm{~km}^{2}$, 占保护区总面积的 $76.13 \%$, 中覆盖度与高覆盖度类型的面积明显增加, 其增加的 面积分别为 $463.13 \mathrm{~km}^{2} 、 98.81 \mathrm{~km}^{2}$, 分别占保护区总面积的 $62.75 \% 、 13.39 \%$ 。

(2) 不同地区 FVC 变化规律有所不同,甜水河管理站、大泉管理站、羊场湾管理站及长流水管理站西侧的 FVC 比马鞍山管理站、临河白莋滩及长流水管理站东侧的 FVC 增长快, 且拟合好; 保护区中部地区即甜水河 管理站、大泉管理站、羊场湾管理站的稳定类型占比相对较低, 极明显逆转类型占比相对较高, 而北部地区即 马鞍山管理站、临河白茩滩的稳定类型占比则相对较高,极明显逆转类型占比则相对较低。

(3) 保护区防风固沙功能整体上逐渐增强,年均实际风蚀量由保护区晋升为国家级自然保护区初期 (第 一阶段) 的 $2.46 \times 10^{5} \mathrm{t}$ 减少至近期 (第五阶段) 的 $1.87 \times 10^{4} \mathrm{t}$; 防风固沙率逐渐上升, 由最初的 $58.37 \%$ 升至 $75.43 \%$ 。保护区内 6 个管理站的防风固沙率均在显著上升, 其中大泉管理站的防风固沙率增长最快, 为 $21.05 \%$, 然后依次为甜水河管理站、长流水管理站、羊场湾管理站、临河白莋滩和马鞍山管理站, 分别增长了 $16.96 \% 、 16.66 \% 、 16.19 \% 、 15.81 \% 、 15.50 \%$ 。相比较黑河下游重要生态功能区等干旱半干旱地区,该保护区面 积虽小,但年均防风固沙能力较高, 可达 $966.58 \mathrm{t} \mathrm{km}^{-2} \mathrm{a}^{-1}$ 。

本研究能为荒漠类自然保护区管理及生态补偿保护标准核算提供科学参考,对完善荒漠类自然保护区生 态修复制度、健全生态保护补偿机制具有重要的现实意义。

\section{5 讨论}

增加 FVC 是减少和控制风蚀的重要措施 ${ }^{[39]}$ 。根据程皓等对 FVC 对降低风速的观测结果表明植被覆盖 
增加可以有效减少土地风蚀 ${ }^{[40]}$ 、崔崴对比浑善达克沙地未治理区和治理区发现治理区的风速明显降低且积 沙量更少 ${ }^{[41]}$ 、周金等对青海湖沙区的研究表明人工治理措施可以明显降低沙丘近地层风速 ${ }^{[42]}$ 等结论, 该保 护区 FVC 的增加可能在一定程度上有效降低了风速, 使得达到起沙风速的天数逐渐降低, 风蚀频率逐渐 减少。

有关研究表明,近 35 年来,生态工程有效改善了毛乌素周边地区的植被状况 ${ }^{[43-44]}$,而白菆滩自然保护区 自成立以来一直致力于荒漠生态修复 ${ }^{[45]}$,一定程度上可以证实该保护区的植被明显改善的原因是生态保护 建设成效显著。王静璞等对毛乌素沙地 2000-2012 年的研究表明, NDVI 空间变化没有明显规律 ${ }^{[46]}$, 而该保 护区的 NDVI 空间变化规律明显,中部地区植被改善状况明显优于其他地区,可能由于不同管理站的生态保 护建设措施不同。

该保护区与黑河下游重要生态功能区等干旱半干旱地区的防风固沙量相比有一定差异,究其原因,首先 这些地区土地利用类型不同, 比如银川盆地除了沙地、戈壁,还包括有林地、灌木林地等多种土地利用类型; 其 次,这些地区选用的防风固沙量计算模型不同,如京津风沙源区和锡林郭勒盟风沙源治理工程区采用的防风 固沙量计算模型为修正风蚀方程 (RWEQ), 所以结果与其他对比地区有一定差距; 最后,可能是由于计算年份 不同、以及数据的选取差异等因素造成 ${ }^{[9,10,37-38]}$ 。同时,本研究计算的防风固沙量的量级和趋势与其他地区基 本一致,可以认为该结果能基本上反映该保护区防风固沙功能变化状况,具有一定参考价值。

\section{参考文献 (References) :}

～ 1 ] 杨强, 王婷婷, 陈吴, 王运动. 基于 MODIS EVI 数据的锡林郭勒盟植被覆盖度变化特征. 农业工程学报, 2015, 31(22): 191-198.

[ 2 ] Gregory J M, Wilson G R, Singh U B, Darwish M M. TEAM : integrated, process-based wind-erosion model. Environmental Modelling \& Software, $2004,19(2): 205-215$.

[ 3 ] Coen G M, Tatarko J, Martin T C, Cannon K R, Goddard T W, Sweetland N J. A method for using WEPS to map wind erosion risk of Alberta soils. Environmental Modelling \& Software, 2004, 19(2): 185-189.

[ 4 ] Guo Z L, Chang C P, Wang R D, Li J F, Li Q. Modeling regional wind erosion using different model//19th EGU General Assembly, EGU2017. Vienna, Austria: EGU, 2017.

[ 5 ] 申陆, 田美荣, 高吉喜, 钱金平. 浑善达克沙漠化防治生态功能区防风固沙功能的时空变化及驱动力. 应用生态学报, 2016, 27(1)： 73-82.

[ 6 ] 黄麟, 曹魏, 吴丹, 巩国丽. 西藏高原生态系统服务时空格局及其变化特征. 自然资源学报, 2016, 31(4) : 543-555.

[ 7 ] 刘璐璐, 邵全琴, 曹巍, 吴丹, 巩国丽, 㚞江文. 基于生态服务价值的三江源生态工程成本效益分析. 草地学报, 2018, 26(1): 30-39.

[ 8 ] 徐洁, 肖玉, 谢高地, 王洋洋, 江源, 陈文辉. 防风固沙型重点生态功能区防风固沙服务的评估与受益区识别. 生态学报, 2019, 39 (16) : 5857-5873.

[ 9 ］董治宝. 建立小流域风蚀量统计模型初探. 水土保持通报, 1998, 18(5): 55-62.

[10] 韩永伟, 拓学森, 高吉喜, 刘成程, 高馨婷. 黑河下游重要生态功能区植被防风固沙功能及其价值初步评估. 自然资源学报, 2011,26 (1) : 58-65.

[11] 李柏延. 银川盆地土地变化生态效应时空差异分析 [D ]. 西安: 陕西师范大学, 2016.

[12] 马晓飞. 艾比湖湿地景观格局变化与生态服务价值关系研究 [D ]. 乌鲁木齐: 新疆师范大学, 2017.

[13] 田帅, 韩雯雯, 韩凯, 董方. 毛乌素沙地防沙治沙现状及对策——以宁夏灵武白菆滩国家级自然保护区为例. 现代商贸工业, 2014, 26 (14) : 186- 187 .

[14] 刘先银. 宁夏白芝滩自然保护区科学考察集. 北京: 中国林业出版社, 1999.

［15］魏蒙. 沙漠绿洲——宁夏灵武白䓅滩国家级自然保护区治沙掠影. 宁夏林业, 2017, (1) : 38-39.

[16] 王兴东. 宁夏灵武白夰滩自然保护区综合科学考察报告. 北京: 中国林业出版社, 2018.

[17］王景琦. 浅析沙尘暴对北方农业生产的影响. 吉林省教育学院学报, 2010, 26(6)：157-158.

[18］李振山, 张琦峰, 包慧娟. 我国北方典型沙漠化地区近 30a 风速变化特征. 中国沙漠, 2006, 26(1): 20-26.

[19］罗亚, 徐建华, 岳文泽. 基于遥感影像的植被指数研究方法述评. 生态科学, 2005, 24(1): 75-79.

[20] 保家有, 李晓松, 吴波. 基于沙地植被指数的荒漠化评价方法. 东北林业大学学报, 2008, 36(1): 69-72.

[21] 何颖清, 秦雁, 扶卿华, 刘超群, 尹斌. 动态端元组合混合像元分解法在植被覆盖度动态监测中的应用一以长汀县为例. 热带地理, $2016,36(5): 860-868$. 
[22] 李晓松, 高志海, 李增元, 白黎娜, 王琫瑜. 基于高光谱混合像元分解的干旱地区稀疏植被覆盖度估测. 应用生态学报, 2010, 21(1)： 152-158.

[23] 刘洋, 吕一河, 郑海峰, 陈利顶. 用回归树模型分析陕北黄土丘陵沟壑区气候因子对 NDVI 变异的影响. 应用生态学报, 2010, 21(5)： 1153-1158.

[24] 陈建军, 黄荣, 赵许宁, 张慧子, 田志林. 黄河源区高寒草地植被覆盖度反演模型精度评价. 科学技术与工程, 2019, 19(15): 37-45.

[25] 穆少杰, 李建龙, 陈奕兆, 刚成诚, 周伟, 居为民. 2001-2010 年内蒙古植被覆盖度时空变化特征. 地理学报, 2012, 67(9): 1255-1268.

[26] 王晓江, 胡尔查, 李爱平, 李全基. 基于 MODIS NDVI 的内蒙古大青山自然保护区植被覆盖度的动态变化特征. 干旱区资源与环境, $2014,28(8): 61-65$.

[27] 木热提江. 阿不拉, 张晓萍, 陈利利, 萄鹏飞, 孙䑨萍. 基于 GIMMS NDVI 的黄土高原地区荒漠化时空特征分析. 中国水土保持科学, $2015,13(3): 24-31$.

［28］李培先, 郑江华, 刘萍. 2000-2014 年乌鲁木齐市植被覆盖度时空变化分析. 林业资源管理, 2016, (4) : 88-95.

［29］莎日娜. 基于 NDVI 的乌拉特后旗植被覆盖度时空变化分析. 林业资源管理, 2017，(6)：89-93，102-102.

[30］阿如汗. 基于 NDVI 的内蒙古科尔沁国家级自然保护区植被覆盖度时空变化分析. 内蒙古科技与经济, 2018，(4)：47-48, 50-50.

[31] 覃志豪, 李文娟, 徐斌, 陈仲新, 刘佳. 陆地卫星 TM6 波段范围内地表比辐射率的估计. 国土资源遥感, 2004，(3)：28-32，36-36， 41-41.

[32］方杰诗, 周晓霖. 基于遥感影像和 NDVI 阈值法的银川市植被覆盖度反演与监测. 节水灌溉, 2014, (11) : 68-72, 76-76.

[33] 郭紫晨, 刘树林, 康文平, 陈翔, 张雪琴. 2000-2015 年毛乌素沙区植被覆盖度变化趋势. 中国沙漠, 2018, 38(5): 1109-1107.

[34] 王亚琴. 高海拔地区植被变化主要影响因子脱钩研究——青海省为例 [D]. 北京: 中国科学院地理科学与资源研究所, 2013.

[35］丁国栋. 风沙物理学(第二版). 北京: 中国林业出版社, 2010.

[36] 周成龙, 杨兴华, 杨帆, 霍文, 钟昕洁, 潘红林, 何清. 基于野外试验对临界起沙风速的计算解析. 干旱气象, 2018, 36(1): 90-96.

[37] 张彪, 李庆旭, 王爽, 谢高地. 京津风沙源区防风固沙功能的时空变化及其区域差异. 自然资源学报, 2019, 34(5): 1041-1053.

[38］张彪，王爽. 锡林郭勒盟风沙源治理区防风固沙功能变化评估. 生态与农村环境学报, 2020, 36(3): 291-299.

[39］韩永伟, 拓学森, 高吉喜, 高馨婷. 黑河下游重要生态功能区防风固沙功能辐射效益. 生态学报, 2010, 30(19): 5185-5193.

[40］程皓, 李霞, 侯平, 裴玉亮. 塔里木河下游不同覆盖度灌木防风固沙功能野外观测研究. 中国沙漠, 2007, 27(6): 1022-1026.

[41］崔崴. 浑善达克塔落岩黄花生长与土壤特性及防风固沙作用研究 $[\mathrm{D}]$. 呼和浩特: 内蒙古农业大学, 2009.

[42] 周金金, 田丽慧, 张登山, 吴汪洋, 张明远, 张佩. 青海湖沙区不同植被防风固沙效益研究. 干旱区资源与环境, 2018, 32(8): 180-185.

[43］芦金金, 殷淑燕. 毛乌素沙地周边地区相对湿度与 NDVI 变化研究. 西北大学学报: 自然科学版, 2018, 48(3): 449-458.

[44] 石玉琼, 郑亚云, 李团胜. 榆林地区 2000-2014 年 NDVI 时空变化. 生态学杂志, 2018, 37(1) : 211-218.

[45］黄芹. 坚持绿色发展 建设美丽白夰滩. 中共银川市委党校学报, 2018, 20(6)：62-64.

[46] 王静璞, 张晓风, 宗敏. 21 世纪初毛乌素沙地 NDVI 时空变化特征及影响因素. 科技创新导报, 2015, 12(34)：160-161, 163-163. 